\title{
Análise Exploratória da Eficiência Produtiva das Usinas de Cana-de-açúcar na Região Centro-Sul do Brasili ${ }^{1,2}$
}

\author{
Caroline Nascimento Pereira ${ }^{3}$ e
} José Maria Ferreira Jardim Silveira ${ }^{4}$

Resumo: O setor sucroenergético se configura estratégico perante a demanda crescente por novas fontes de energia alternativas ao petróleo e derivados, em virtude das pressões sobre essa matéria-prima. Dada a futura conjuntura que se desenha, o etanol de cana-de-açúcar em muito se adequa e possui vantagens para conquistar novos mercados, mas desde que tenha uma produção eficiente e que faça bom uso dos recursos existentes. Assim sendo, o trabalho analisa a produtividade total dos fatores (PTF) e seus componentes para 17 usinas da região Centro-Sul do Brasil durante o período 2001-2008. A amostra é considerada significativa, pois o volume de cana moída representa 11,5\% do total moído no Brasil. A metodologia se baseia em Coelli et al. (1998), a partir da Análise Envoltória de Dados (DEA), com o uso do índice de Malmquist, que avalia os índices de produtividade ao longo do tempo, decompondo-os em índices que captam variação da eficiência técnica e mudanças tecnológicas. $\mathrm{O}$ trabalho conclui que a amostra é composta em sua maioria por followers, ou seja, as usinas não criam e adotam inovações radicais, elas apenas seguem um movimento conjunto em direção a tecnologias já testadas no mercado e de comprovada eficiência por outras usinas.

Palavras-chaves: Setor sucroenergético; Análise Envoltória de Dados; Índice de Malmquist.

\footnotetext{
Abstract: The sugarcane industry is strategic regarding the increasing demand for new sources of energy alternatives to oil and byproducts, given the pressures on the raw material. Due the future scenario that is taking shape, the ethanol produced from the sugarcane has advantages to conquer new markets, but since it has an efficient production and that makes a good use of existing resources. Therefore, the study analyzes the Total Factor Productivity (TFP) and their components for 17 mills in the Center-Southern region in

1. Data de submissão: 3 de julho de 2015. Data de aceite: 15 de janeiro de 2016 .

2. Agradecemos ao Dr. Henrique Vianna de Amorim pelo fornecimento dos dados sobre as usinas para a análise realizada no presente artigo.

3. Universidade Estadual de Campinas. Campinas, SP, Brasil. E-mail: carolinenasper@gmail.com

4. Universidade Estadual de Campinas. Campinas, SP, Brasil.E-mail: jmsilv52@gmail.com
} 
Brazil during the period from 2001 to 2008. The sample is considered significant because the volume of cane crushed represents 11.5\% of the total in Brazil. The methodology is based on Coelli et al. (1998), from Data Envelopment Analysis (DEA), using the Malmquist index, which assesses the productivity levels over time, decomposing them into indices that capture variation of the technical efficiency and technological changes. The paper concludes that the sample is composed mostly of followers, ie, the plants do not create and adopt radical innovations. They just follow a set move toward technologies already tested in the market and proven by other plants.

Key-words: Sugarcane sector; Data Envelopment Analysis; Malmquist Index.

DOI - http://dx.doi.org/10.1590/1234-56781806-9479005401008

Classificação JEL: Q120, C610.

\section{Introdução}

A perspectiva de aumento crescente na demanda por etanol, devido à projeção de aumento nas vendas de veículos bicombustíveis impulsionado pelo aumento de renda per capita da população brasileira, aliado à perspectiva de adoção de níveis obrigatório de mistura do etanol anidro na gasolina por um número cada vez maior de países, além de outros usos, levaram ao questionamento das capacidades produtivas da indústria brasileira de etanol, uma vez que o setor apresenta dificuldades para garantir a produção necessária para o mercado interno e o potencial mercado externo que se abriria com as medidas mandatórias.

O Brasil se caracteriza por um ambiente com firmas não homogêneas e unidades de produção apresentando estruturas gerenciais e resultados muito distintos umas das outras, o que faz surgir o questionamento sobre o nível de eficiência produtiva do setor sucroenergético para enfrentar os desafios que se apresentam e tendem a se tornar cada vez mais complexos. De fato, a partir da lacuna deixada pelo Estado no setor, após o período de desregulamentação nos anos 1990, muitas empresas que conseguiram permanecer neste mercado introduziram os conceitos da globalização e procuraram ficar na dianteira do

5. Ver Figueira (2005). processo de liderança através de três palavras-chaves: eficiência, produtividade e competitividade. Nesse ponto é importante observar como o processo de concorrência dos anos 1990 foi sofrendo um aprimoramento, com a busca incessante por maior participação nos mercados e ganhos de escala.

Entretanto, como já mencionado, não se observa uniformidade no setor. Há desde usinas centenárias com produção de açúcar e etanol, até unidades novas, chamadas de projetos greenfield, com tecnologia de ponta e maior eficiência nos processos. A eficiência de uma unidade produtiva sucroenergética pode ser analisada através de diversos pontos, tanto na área agrícola quanto na industrial. Na área agrícola, observa-se o uso da terra, número de trabalhadores rurais, máquinas e implementos, fertilizantes, entre outros. $\mathrm{Na}$ área industrial, observa-se o melhor aproveitamento dos Açúcares Totais Recuperáveis (ATR) que entram na usina e o número de trabalhadores existentes para a obtenção dos produtos açúcar e etanol.

Assim sendo, dentro da perspectiva de crescente demanda, somado ao interesse dos mercados externos no etanol, é que surge a motivação desse trabalho. $\mathrm{O}$ foco da análise está no questionamento da capacidade do setor sucroenergético em atender à crescente demanda, olhando para as capacidades tecnológicas das usinas/destilarias, em que, apesar da liderança brasileira na 
tecnologia de produção de etanol de cana-de-açúcar, o setor ainda apresenta algumas fragilidades, que resultam em choques de oferta, os quais podem ser atribuídos tanto a fatores climáticos e não controláveis, como a fatores internos do setor e, possivelmente, contornáveis.

Com isso, é possível inferir que o avanço do setor somente será possível com o forte investimento em novos processos e tecnologias, incluindo o etanol de segunda geração, mas muito pode ser alcançado pela melhoria do padrão de eficiência das usinas já existentes, para que o setor não se baseie somente na expansão da fronteira agrícola da cultura de cana-de-açúcar, mas utilize da melhor forma possível os recursos já existentes no setor. Deste modo, o objetivo deste trabalho versa sobre a importância da eficiência produtiva industrial, ou seja, dada uma quantidade de insumos, será que as usinas exploram todas as potencialidades da indústria e, mais além, será que as usinas conseguem acompanhar as unidades mais inovadoras?

\section{Fundamentação teórica}

O setor sucroenergético tem algumas peculiaridades em termos de capacitação tecnológica. Para Miglino (2003), trata-se de um setor dominado pelas inovações trazidas pelo fornecedor, com a capacidade externa localizada em empresas especializadas em engenharia, além da engenharia interna voltada para o desenvolvimento de equipamentos e engenharia de processo, porém, em grande parte das usinas, esse trabalho interno não é capaz de promover inovações consideráveis no processo.

Ademais, observa-se a preponderância das inovações incrementais nesse setor, em que grande parte das usinas opta por uma posição de observação, uma vez que a adoção de inovações e mudança tecnológica em um ambiente permeado de incertezas apresenta alto risco. Conforme apontam Nelson e Winter (1982), o processo de inovação, ao envolver um alto grau de incerteza, não só antes como após sua introdução, gera um contínuo desequilíbrio de mercado.
Dado que o bem transacionado neste mercado é de alta demanda, os produtores e usineiros não se veem obrigados a realizarem inovações radicais ou estarem em uma condição de early adopters, ou seja, os líderes do processo de adoção. Importante considerar que esse setor possui poucas unidades que internalizam, em grande medida, as atividades de P\&D, pois, como colocam Rissardi Jr. e Shikida (2007), as usinas participam de um sistema de inovação, possivelmente muito próximo dos sistemas setoriais de inovação, discutido por Malerba (2006).

A inovação é um elemento central de diferenciação entre as empresas, em que a explicação para a heterogeneidade do setor pode ser melhor explicada recorrendo à literatura neo-schumpeteriana, a partir das contribuições de Dosi (1984) sobre paradigmas e trajetórias tecnológicas, estratégias tecnológicas, rotinas, seleção e busca de inovações (NELSON e WINTER, 1982) e processo de aprendizado (ROSENBERG, 1982). As inovações radicais possivelmente estão relacionadas com a forma de gestão da usina, em que as unidades tradicionais, porém, não menos eficientes, são mais cautelosas com as estratégias de inovação de tecnologias. Com isso, há inovações incrementais em equipamentos existentes, ao mesmo tempo em que há novas unidades com processos produtivos novos, mas esses são exemplos em pequena escala (MIGLINO, 2003).

Seguindo a categorização de Levins e Cochrane (1996) para o processo inovativo das empresas, há três subgrupos de empresas, sendo as early adpters, ou seja, as líderes no processo de inovação. O segundo grupo são os followers, que se refere ao grupo que possui comportamento mimetizador, ou seja, introduzem somente projetos significativos que já foram testados por outras empresas do setor. E, por fim, o grupo dos laggards, que resumidamente refere-se aos retardatários no processo de desenvolvimento de produtos. A aplicação dessas categorias no setor sucroenergético através do conhecimento acerca do mesmo permite caracterizar a maioria das unidades produtivas como followers e laggards, devido às incertezas inerentes ao processo de adoção de inovações. 
O setor, desde os anos 1980, já vinha nesse processo de modernização das linhas de produção, o qual pode ser caracterizado como uma modernização passiva e adaptativa, não tendo como objetivo uma trajetória virtuosa que buscasse a competitividade através da capacitação tecnológica (MIGLINO, 2003).

Ao analisar os condicionantes da agroindústria canavieira do Paraná, Rissardi Jr. e Shikida (2007) observaram que algumas usinas e destilarias buscaram novos caminhos para garantir a sobrevivência e expansão dos negócios, com as estratégias de especialização na produção de açúcar e etanol e no aumento da produtividade das áreas agrícolas e industriais.

Ademais, eficiência produtiva é uma forma de construir vantagens competitivas e que, nesse sentido, as firmas que obtêm os maiores scores de eficiência possuem também vantagens competitivas sobre as demais, pois são mais fortes. No geral, observa-se forte heterogeneidade tecnológica e produtiva, que faz com que as firmas possuam níveis de eficiência muito distintos.

Cano e Tupy (2005) argumentam que a heterogeneidade no setor ocorre pela forma como os insumos são utilizados pelas diferentes firmas, o que resulta em diferenças significativas de eficiência técnica e de escala pelas usinas. Não esquecendo, sobretudo, da capacidade industrial que se terá quando as economias de escopo do setor estiverem bem trabalhadas, uma vez que a cana tem capacidade de gerar subprodutos, além do etanol, açúcar e melaço, como bagaço e palha, os quais podem significar a produção de etanol de segunda geração, além dos usos já efetuados, como fertilizantes, energia elétrica, entre outros.

De todo modo, toda a discussão de eficiência sobre o setor sucroenergético ainda é incipiente, uma vez que grande parte dos estudos e análises sobre a eficiência do setor não chegam a dados conclusivos sobre o que efetivamente determina o melhor desempenho de uma usina. Por esse motivo, um fator que é de difícil mensuração, mas que pode estar intrinsecamente relacionado com os resultados do setor são as capacidades organizacionais, uma vez que se trata de um setor heterogêneo.
O estudo de Sesmero et al. (2011) apresenta o modelo DEA aplicado às usinas de etanol que utilizam o milho como matéria-prima, ou seja, ele utiliza o modelo DEA para decompor a eficiência econômica das plantas em fontes tradicionais, como eficiência técnica e alocativa, e um novo componente chamado eficiência de mercado, que se refere à capacidade das empresas em contratar preços favoráveis de milho e etanol em relação aos preços do mercado spot e as implicações para o desempenho econômico em geral. Um apontamento realizado pelo estudo observa que as unidades que apresentam os maiores volumes de produção apresentam o melhor desempenho, devido ao fato de elas assegurarem preços mais favoráveis através da melhoria no desempenho de mercado. Ademais, as unidades produtivas podem alcançar melhorias significativas no desempenho de mercado através da experiência e do learning-by-doing. Os resultados são consistentes com dois fatos: economias de escala podem não ser a única razão por trás do aumento do tamanho médio das plantas da indústria de etanol, e o segundo fato é que deve haver incentivos para consolidação horizontal entre as plantas.

Cano e Tupy (2005) fizeram um estudo de avaliação da eficiência produtiva da agroindústria canavieira paulista, com o objetivo de estabelecer rankings de eficiência das firmas que compõem a agroindústria através da técnica DEA. O estudou procurou analisar, através dos dados de 78 empresas do estado de São Paulo, o grau de heterogeneidade dos níveis de eficiência das firmas, como a concentração regional das firmas eficientes, a relação entre eficiência e escala produtiva a as possíveis causas para a ineficiência. $\mathrm{O}$ trabalho utilizou dados de volume de cana moída e número de empregados do setor administrativo e industrial como variáveis de insumo e produção de etanol e açúcar como variáveis de produto. A principal conclusão do trabalho é que as maiores fontes de ineficiência das firmas se devem aos fatores capacidade instalada e mão de obra, em que a capacidade instalada não é utilizada; porém, o trabalho não identificou a real causa. 
Segundo Abarca (2003), o desenvolvimento tecnológico implementado na agroindústria canavieira da cana-de-açúcar na década de 1990 aconteceu através dos transbordamentos das tecnologias existentes em outros setores, ou seja, o processo de inovação observado foi um processo incremental e fragmentado, pois este não atingiu o sistema agroindustrial da cana de forma plena.

Nos últimos anos tem sido observada a preocupação com a difusão da pesquisa e tecnologia desenvolvida e/ou adaptada pelo setor produtivo e a tecnologia desenvolvida por fornecedores de equipamentos, produtos e serviços, como a realização de feiras e simpósios para a divulgação das novidades do setor (ABARCA, 2003). Nesse âmbito, entra o papel do CTBE, fomentando com tecnologia de ponta o setor sucroenergético, através do investimento estatal do Ministério da Ciência e Tecnologia, que, se comparado ao volume de investimentos realizados pelo setor nos EUA, é considerado muito pequeno. Além disso, este último já se encontra em fase mais adiantada na obtenção de etanol de segunda geração.

Rissardi Jr. e Shikida (2007) realizaram um estudo para analisar os principais condicionantes da evolução da agroindústria canavieira do estado do Paraná após a desregulamentação sob o enfoque neo-schumpeteriano. Os resultados observados foram a razoável capacidade de adaptação às condições de livre concorrência, investindo em inovações tecnológicas de produtos e processos, mas que, mesmo assim, foi observada heterogeneidade tecnológica, em que algumas usinas se distanciaram das demais em função de adoção de estratégias tecnológicas ofensivas.

A conclusão do trabalho é muito interessante ao notar que a grande maioria das usinas no estado $(76 \%)$ adquirem e constroem competências e habilidades no desenvolvimento de capacitações produtivas, tecnológicas e organizacionais através do learning-by-interacting, que ocorre através da interação com fornecedores de insumos, componentes e equipamentos, concorrentes, clientes, consultores, universidades, institutos de pesquisa, prestadores de serviços, agências e laboratórios governamentais.
Salgado Jr et al. (2009) realizaram um estudo sobre a relação entre o tamanho e a eficiência operacional de usinas de açúcar e álcool na região nordeste do estado de São Paulo. O estudo abrangeu 26 unidades produtivas, quantificando o consumo dos principais recursos e a geração dos produtos, permitindo sua classificação em função do tamanho (capacidade de moagem). O trabalho criou um ranking de eficiência operacional através do uso da técnica de análise envoltória de dados (DEA).

Bruzoni Jr e Gonçalves (2011) realizaram um estudo da eficiência produtiva e análise econômica e financeira de usinas de cana-de-açúcar do estado de São Paulo. O trabalho analisou 17 usinas através da análise envoltória de dados (DEA), baseado em três insumos (estoques, capital imobilizado e salários) e um produto (faturamento bruto). Os resultados obtidos mostraram que apenas quatro das 17 usinas obtiveram eficiência técnica máxima e, além disso, chegou-se à conclusão de que entre as ineficientes (13 usinas), a explicação se encontra na ineficiência no uso de insumos.

Em suma, ainda há poucos estudos sobre a eficiência do setor e os resultados sugerem que, no geral, as usinas não estão no seu potencial máximo, ou seja, elas ainda têm um longo caminho a percorrer para obter o máximo de eficiência ao usar os recursos disponíveis da melhor forma possível. É razoável afirmar que as usinas do setor ainda parecem ser em sua grande maioria followers e até mesmo laggards, ou seja, possuem resistência em adotar as inovações, principalmente as unidades mais tradicionais. Esse quadro pode estar em transformação, com a entrada de novos grupos, principalmente os estrangeiros e de outros setores, o que pode trazer uma nova dinâmica para o setor.

\section{Metodologia}

A análise de eficiência produtiva ou desempenho é uma medida tradicional e amplamente utilizada em diversos setores da economia para comparar a relação entre o uso de insumos e 
produtos obtidos para determinadas unidades produtivas. Esta medida é uma avaliação ex-post, que pode ser aplicada no nível micro das Decision Making Units (DMUs), Unidades Tomadoras de Decisão, que pode se referir a empresas privadas produtoras de bens, caso particular desse trabalho, além de outros tipos de empresas, como organizações não lucrativas, escolas ou hospitais. O método também permite a análise interna de desempenho dos setores de uma única unidade produtiva (COELLI et al., 1998).

Para um melhor entendimento da metodologia utilizada no trabalho, essa seção começará com a definição de produtividade, que é a taxa de produtos obtidos pelos insumos utilizados. Segundo Coelli et al. (1998), caso o problema envolva mais de um insumo, então o método de procedimento é a construção de um índice para obter uma medida de produtividade.

O termo eficiência, apesar de ser usado como sinônimo para produtividade, é um conceito muito particular e distinto de produtividade. Para melhor entendimento da diferença será utilizado um exemplo ilustrativo. Considere uma função de produção no qual um insumo $(x)$ é usado para produzir um produto (y). A linha da curva $0 F^{\prime}$ na Figura 1 representa a fronteira de produção, que pode ser usada para definir a relação entre insumo e produto, sendo, assim, a representação gráfica do produto máximo obtido para um dado nível de insumo. Assim sendo, a curva $0 F^{\prime}$ reflete o estado atual de tecnologia na indústria, em que as empresas que estiverem sobre a fronteira de eficiência podem ser consideradas tecnicamente eficientes, e aquelas sob a curva não são tecnicamente eficientes.

Na Figura 1, o ponto $A$ representa uma unidade produtiva ineficiente, porque tecnicamente esta poderia aumentar o seu produto para o nível relacionado ao ponto $B$, sem necessitar de aumento no volume de insumos. Por sua vez, os pontos $B$ e $C$ representam pontos eficientes para diferentes níveis de insumos.

Dentro da mesma Figura 1 é possível explicar economias de escala, que significa o movimento do ponto $B$ para o ponto $C$ que, apesar de se posicionarem sobre a mesma fronteira de eficiência, podem ser considerados distintos, pois o ponto $C$ é o ponto máximo de produtividade, também chamado de ponto de escala ótima técnica. Portanto, uma unidade produtiva pode ser considerada tecnicamente eficiente e continuar apta para melhorar a produtividade através de economias de escala.

Figura 1. Fronteiras de Produção e Eficiência Técnica

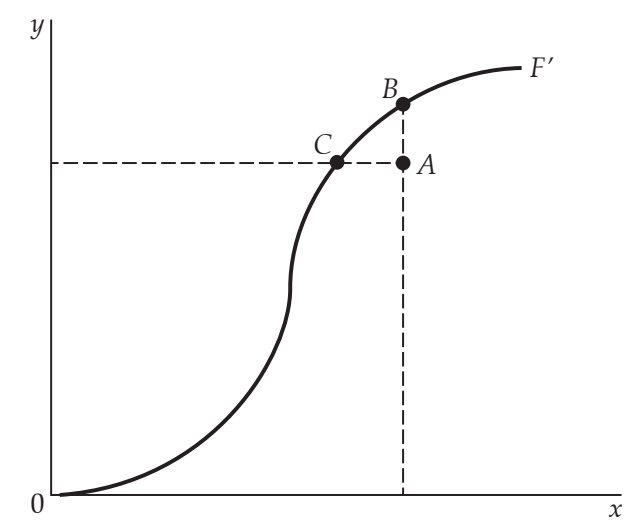

Fonte: Coelli et al. (1998). 
Outro conceito importante é de mudança tecnológica, o qual considera a análise intertemporal, ou seja, comparam-se as produtividades ao longo do tempo considerando os avanços na tecnologia. A mudança de tecnologia pode deslocar a fronteira de produção ao longo do período analisado. As alterações positivas ou negativas na produtividade de uma unidade produtiva entre dois períodos de tempo $t$ e $t+1$ podem ser explicadas por melhorias na eficiência, mudança tecnológica ou exploração de economias de escala. Os ganhos de produtividade podem ser explicados exclusivamente por cada uma delas ou pelo conjunto dos três componentes.

\subsection{Análise Envoltória de Dados (DEA)}

Há diversos métodos de análise de desempenho, mas esse trabalho utilizará o método da Análise Envoltória de Dados (DEA) com o uso do Índice de Malmquist, pois trata-se de uma amostra com dados em painel, a qual deve ser analisada em diversos períodos do tempo. O método de Análise Envoltória de Dados (DEA) é um método relativamente recente e tem sido amplamente usado nos mais variados estudos sobre eficiência das Unidades Tomadoras de Decisão (DMUs). Este método tem fornecido informações mais precisas acerca das atividades, representando um avanço na análise de eficiência.

Este é um método que assume que nem todas as empresas são eficientes, havendo a estimativa de fronteiras de eficiências, em que a análise das firmas é relativa à fronteira. O método DEA pode ser aplicado em casos de múltiplos insumos e múltiplos produtos e tem como característica a vantagem de poder identificar as origens e quantificar a ineficiência em cada insumo e cada pro- duto para cada parte da empresa e identificar os membros referência.

Segundo Coelli et al. (1998), a discussão de eficiência inicia-se com o trabalho de Farrell (1957), o qual, a partir do trabalho de Debreu (1951) e Koopmans (1951), definiu uma medida simples de eficiência da firma que considerava múltiplos insumos. Farrell (1957) contribuiu com a proposição acerca da composição da medida de eficiência, que se divide entre eficiência técnica, capacidade de produzir o máximo de produtos a partir de um dado grupo de insumos, e eficiência alocativa, que reflete a habilidade da firma em usar os insumos em ótimas proporções, dados seus respectivos preços e tecnologia de produção. Tais medidas combinadas fornecem uma medida total de eficiência econômica.

Para a aplicação da Análise Envoltória de Dados (DEA) os modelos utilizados são classificados de acordo com o tipo de superfície envoltória e a sua orientação a insumos ou produtos (SALGADO JR et al., 2009). A Eficiência Técnica (ET) é uma função que mede a fronteira de produção, em que esta pode ser medida pela orientação ao insumo, focada na redução do insumo, ou orientação ao produto, focada no aumento do produto.

A medida da eficiência técnica é possível através do conhecimento da unidade da isoquanta SS' (Figura 2) das firmas totalmente eficientes. Se uma firma utiliza uma dada quantidade de insumos (ponto $P$ ) para produzir uma unidade de produto (ponto $Q$ ), a ineficiência técnica da firma pode ser representada pela distância $Q P$ da firma em relação à fronteira de eficiência, que equivale à quantidade pela qual todos os insumos podem ser proporcionalmente reduzidos sem a redução do produto. 
Figura 2. Eficiência Técnica

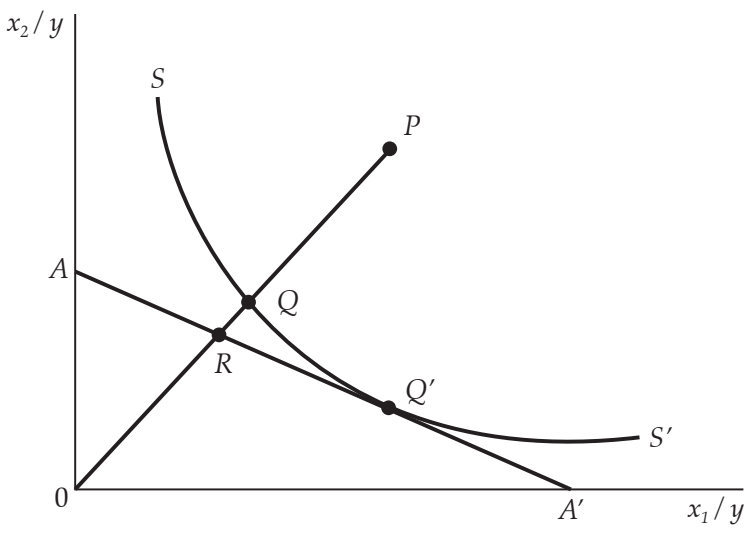

Fonte: Coelli et al. (1998).

A medida de ineficiência pode ser expressa em termos percentuais pela relação $\frac{Q P}{O P}$, que representa a porcentagem pela qual todos os insumos precisam ser reduzidos para alcançar uma produção tecnicamente eficiente. A Eficiência Técnica (TE) da firma (i) é comumente medida pela relação

$$
T E_{i}=\frac{0 Q}{O P}
$$

que é igual a um menos $Q P / 0 P$. Essa medida estará dentro do intervalo entre zero e um e, portanto, proverá um indicador do grau de ineficiência da firma. Quando um valor é igual a 01 significa que a DMU é tecnicamente eficiente, e que o ponto $Q$ é tecnicamente eficiente porque está situado sobre a isoquanta (fronteira de eficiência).

Em suma, a orientação ao insumo significa saber o quanto dos insumos utilizados pode ser proporcionalmente reduzido sem alterar a quantidade de produto final obtido. Em outras palavras, uma DMU é eficiente se sua escala de operação for a que melhor aproveita os insumos.

A Figura 3 apresenta um modelo em que a produção envolve dois produtos $\left(y_{1}\right.$ e $\left.y_{2}\right)$ e um único insumo $\left(x_{1}\right)$. A linha $Z Z^{\prime}$ é a curva das pos-

Figura 3. Eficiência Técnica - Produto-Orientada

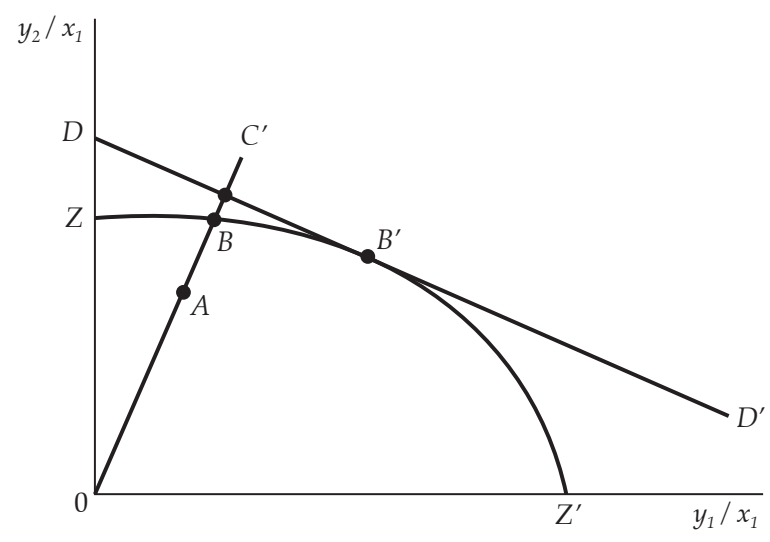

Fonte: Coelli et al. (1998). 
sibilidades de produção e o ponto $A$ corresponde a uma unidade produtiva ineficiente, em que a distância $A B$ representa ineficiência técnica, ou seja, é a quantidade pela qual os produtos podem aumentar sem a necessidade de um insumo extra.

Portanto, a medida de eficiência técnica produto-orientada é dada pela relação

$$
T E_{0}=\frac{O A}{0 B}
$$

Segundo Coelli et al. (1998), muitos trabalhos utilizam a medida de eficiência insumo-orientada porque grande parte das empresas tem regras a cumprir e, portanto, os insumos parecem ser as primeiras variáveis de decisão. Mas a escolha por tal medida não é uma regra, pois muitas empresas preferem obter um nível maior de produto dado um nível fixo de insumos; portanto, a orientação ao produto é mais apropriada.

Em suma, a escolha pela orientação ao insumo ou ao produto deve ser de acordo com quais quantidades de insumos ou produtos os tomadores de decisões possuem maior controle. Com isso, neste trabalho foi aplicada a medida de eficiência técnica orientada ao insumo, pois os recursos utilizados na produção são muito variáveis, o que leva à necessidade de melhor uso (eficiente) dos mesmos para aumentar o nível de competitividade das empresas.

\section{2. Índice Malmquist - \\ Produtividade Total dos Fatores (PTF)}

O índice de Malmquist foi inicialmente sugerido para análises de uso de insumos pelo seu autor (MALMQUIST, 1953), tendo sido posteriormente aplicado num contexto de produtividade por Caves et al. (1982), o que, somado às idéias de Farrell (1957) sobre medidas de eficiência, levou ao índice de produtividade DEAMalmquist, desenvolvido por Färe et al. (1994). Os primeiros trabalhos realizados por Aigner e Chu (1968) usaram métodos de programação linear aplicados à análise de dados em painel da área social e, posteriormente, medidas de crescimento da Produtividade Total dos Fatores (PTF) como a soma do componente de mudança de eficiência e mudança técnica (COELLI et al., 1998).

O índice de Malmquist é definido pelo uso de funções de distância, que permitem a descrição de múltiplos-insumos e múltiplos-produtos sem a necessidade de especificar a função objetivo, como minimização de custos ou maximização do lucro. Ainda, esse índice permite a decomposição das mudanças de produtividade dentro da mudança no indicador de eficiência e mudança tecnológica, permitindo, dessa forma, conhecer a natureza da mudança de produtividade (MELO JUNIOR, 2005).

Esse índice mede a mudança na Produtividade Total dos Fatores (PTF) entre dois pontos pelo cálculo da taxa das distâncias de cada ponto relativo para uma tecnologia comum. Segundo Coelli et al. (1998), o índice de mudança na PTF entre o período $s$ e o período $t$ é dado pela fórmula:

$$
m_{0}\left(y_{s}, x_{s}, y_{t}, x_{t}\right)=\left[\frac{d_{0}^{s}\left(y_{t}, x_{t}\right)}{d_{o}^{s}\left(y_{s}, x_{s}\right)} \times \frac{d_{o}^{t}\left(y_{t}, x_{t}\right)}{d_{o}^{t}\left(y_{s}, x_{s}\right)}\right]^{1 / 2}
$$

A equação 3 representa a distância a partir do período $t$ para o período $S$. Um valor de $m_{\mathrm{o}}$ maior que um (1) indica PTF positivo do período $S$ para o período $t$, enquanto um valor menor que um (1) indica um declínio da PTF. A equação 3 é o exemplo geométrico dos dois índices de PTF do período $S$ e do período $t$.

O índice pode ser escrito como segue:

$m_{0}\left(y_{s,}, x_{s}, y_{t}, x_{t}\right)=\frac{d_{o}^{t}\left(y_{t}, x_{t}\right)}{d_{o}^{s}\left(y_{s}, x_{s}\right)}\left[\frac{d_{o}^{s}\left(y_{t}, x_{t}\right)}{d_{o}^{t}\left(y_{t}, x_{t}\right)} \times \frac{d_{o}^{s}\left(y_{s}, x_{s}\right)}{d_{o}^{t}\left(y_{s}, x_{s}\right)}\right]^{1 / 2}$

em que a taxa localizada fora das chaves mede a mudança de eficiência técnica entre o período $S$ e $t$. O restante do índice da equação 4 é uma medida de mudança técnica. Este é o significado geométrico da alteração na tecnologia entre os dois períodos, avaliado como $x_{\mathrm{t}}$ e $x_{\mathrm{s}}$. Então, os dois termos da equação 4 são:

Mudança de Eficiência $=\left[\frac{d_{0}^{t}\left(y_{t}, x_{t}\right)}{d_{0}^{s}\left(y_{s}, x_{s}\right)}\right]$ 
e

Mudança Técnica $=\left[\frac{d_{0}^{s}\left(y_{t}, x_{t}\right)}{d_{0}^{t}\left(y_{t}, x_{t}\right)} \times \frac{d_{o}^{s}\left(y_{s}, x_{s}\right)}{d_{0}^{t}\left(y_{s}, x_{s}\right)}\right]^{1 / 2}$

Esta decomposição é ilustrada na Figura 4, em que é exemplificado o modelo CRS/CCR envolvendo um insumo e um produto. As firmas $D$ e $E$ produzem nos pontos respectivos do gráfico nos períodos $S$ e $t$. Em cada período a firma está operando abaixo da fronteira de eficiência. Portanto, há ineficiência técnica nos dois períodos.

Um ponto importante a ser enfatizado é que as propriedades dos retornos de escala são mais importantes para a medida da PTF. Quando são assumidos Retornos Variáveis de Escala (VRS) pode haver problemas, sendo então importante que o modelo CRS seja imposto a qualquer tecnologia que seja usada para estimar funções de distância para o cálculo de um índice PTF de Malmquist. Caso contrário, as medidas resultantes podem não refletir adequadamente os ganhos ou perdas da PTF resultantes dos efeitos de escala.

Assim sendo, melhorias na produtividade estariam associadas a índices de Malmquist que excedam a unidade. A mesma leitura pode ser feita com cada componente da PTF, em que se espera que o componente de eficiência téc- nica capte a difusão tecnológica e o processo de catching-up, enquanto o processo de mudança técnica capte as inovações. A mudança de eficiência técnica pode ser decomposta em eficiência de escala e eficiência técnica pura.

A metodologia utilizada no cálculo da variação da PTF e de sua decomposição baseia-se no índice de produtividade total de Malmquist. A PTF é decomposta em dois componentes: variação da eficiência técnica e variação tecnológica. Este procedimento de decomposição permite identificar e quantificar os fatores determinantes do desempenho da PTF ao longo do tempo: o componente que explica uma aproximação da fronteira de produção (variação da eficiência técnica) e aquele relativo ao deslocamento da própria fronteira de produção (variação tecnológica).

Färe et al. (1994) colocam que se o valor do índice de Malmquist for menor que 1, isso denota redução ou deterioração no desempenho, e valores maiores do que 1 denotam melhor desempenho relativo. O Índice de Malmquist avalia os índices de produtividade em diferentes períodos de tempo, decompondo-os em subíndices que refletem a variação da eficiência técnica e mudanças tecnológicas. Essa decomposição do índice de Malmquist contribui para uma análise das alterações nos índices de produtividade, pois permite

Figura 4. Índice de Produtividade de Malmquist

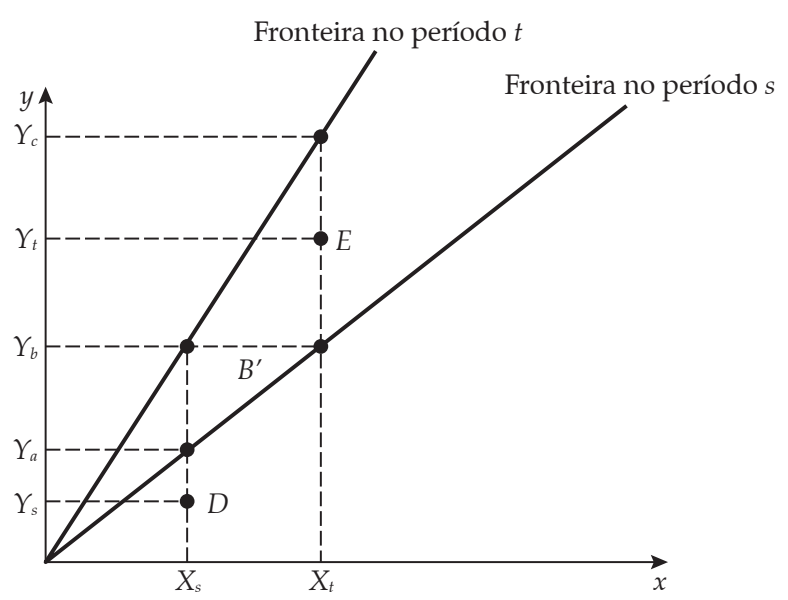

Fonte: Coelli et al. (1998). 
identificar se um aumento é fruto do progresso tecnológico ou da melhoria na eficiência técnica, ou ainda, dos dois simultaneamente.

A análise de eficiência realizada nesse trabalho utilizou o modelo de Análise Envoltória de Dados (DEA), com o índice de Malmquist, com o programa Data Envelopment Analysis Program (DEAP), em sua versão 2.1, escrita por Coelli (1996). O software foi obtido diretamente do Centre for Efficiency and Productivity Analysis $(\mathrm{Cepa})^{6}$, a partir do qual foi possível gerar a eficiência do modelo VRS (BCC), orientado ao insumo, para as 15 DMUs selecionadas.

\section{Resultados e discussão}

O presente trabalho é um estudo exploratório da eficiência produtiva de um grupo de usinas da região Centro-Sul do Brasil, as quais eram clientes da Consultoria Fermentec ${ }^{7}$, que promove melhorias no processo produtivo das indústrias do setor. Desta forma, a amostra possui um viés de seleção, pois se trata de unidades produtivas que investiram na melhoria dos processos dentro da área industrial da usina, ou seja, espera-se que as unidades apresentem bom resultado em níveis de eficiência.

Os dados primários foram fornecidos pela Consultoria Fermentec e pelas próprias usinas analisadas através da Unica ${ }^{8}$. O grupo amostral compreende 17 usinas e destilarias da região Centro-Sul, localizadas nos estados de São Paulo (15), Goiás (1) e Paraná (1). O período de análise

6. http://www.uq.edu.au/economics/cepa/deap.htm

7. A Consultoria Fermentec é uma empresa especializada em fornecer tecnologia em fermentação ao setor sucroenergético. Segundo Barros (2009), a empresa é uma das pioneiras na área de busca e transferência de tecnologia de fermentação alcoólica e de controle da produção de açúcar. A consultoria trabalha com mais de 70 empresas do setor, objetivando otimizar o rendimento industrial e contribuindo para a melhoria da qualidade do produto final.

8. A União dos Produtores de Açúcar (Unica) é uma organização representativa do setor sucroenergético brasileiro, criada em 1997, após a desregulamentação do setor no Brasil. A Unica representa 146 companhias em todo o Brasil, as quais abrangem mais de $50 \%$ da produção nacional de açúcar e etanol. compreende os anos entre 2001 e 2008, período em que ocorreram as principais operações de fusões e aquisições no setor. A amostra original fornecida pela consultoria abrangia um maior grupo de usinas e maior abrangência temporal; entretanto, por haver lacunas nos dados originais, estes não puderam ser utilizados em sua totalidade, pois o modelo adotado não admite valores ausentes no conjunto de dados. Assim sendo, apesar de toda a década de 2000 ser importante, o trabalho se limita ao período entre os anos 2001 e 2008.

Para a análise completa da eficiência produtiva industrial das usinas foi necessário categorizar a análise em duas, com a análise descritiva estatística da amostra apresentando dados de produção e, posteriormente, a análise DEA (Análise Envoltória de Dados) através do índice de Malmquist, analisando a eficiência. O processo de amostragem é não aleatório, pois o universo estudado é naturalmente restrito, uma vez que as usinas foram escolhidas a partir dos clientes da Fermentec, ou seja, são unidades que procuraram melhorias nos últimos anos no seu processo de fermentação e destilação. Esse ponto é importante, pois há limitações de inferência, os quais não invalidam os resultados da pesquisa, uma vez que não se tem o intuito de generalizar os resultados.

A amostra do trabalho pode ser considerada um grupo de elite, uma vez que das 345 usinas da região Centro-Sul, menos de 100 contrataram os serviços de consultoria da Fermentec no período analisado. Essa informação é importante na medida que a Fermentec é uma empresa privada referência em pesquisa na área industrial do setor sucroenergético. A maioria das usinas faz acordos com Universidades, CTC e Embrapa, com maior foco na área agrícola, havendo uma lacuna de serviços de melhoria de eficiência na área industrial.

As variáveis utilizadas na aplicação do método DEA-Malmquist para o cálculo da eficiência relativa das DMUs são divididas em inputs (entradas/ insumos) e outputs (saídas/produtos). Os inputs utilizados são a quantidade de cana moída ao longo dos anos e número de empregados na área 
Tabela 1. Processamento de cana-de-açúcar (em t) - 2001 - 2008

\begin{tabular}{cccccc}
\hline Ano & Amostra & $\begin{array}{c}\text { Taxa de } \\
\text { Crescimento Anual }\end{array}$ & Centro-Sul & $\begin{array}{c}\text { Taxa de Crescimento } \\
\text { Anual }\end{array}$ & $\begin{array}{c}\text { Participação Amostra/ } \\
\text { Centro-Sul }\end{array}$ \\
\hline 2001 & $28.993 .456,44$ & - & Cana-de-Açúcar & \\
2002 & $32.816 .567,32$ & $13,2 \%$ & $244.218 .084,00$ & - & $11,9 \%$ \\
2003 & $37.155 .489,97$ & $13,2 \%$ & $270.406 .693,00$ & $10,7 \%$ & $12,1 \%$ \\
2004 & $38.910 .283,14$ & $4,7 \%$ & $299.120 .591,00$ & $10,6 \%$ & $12,4 \%$ \\
2005 & $41.408 .731,99$ & $6,4 \%$ & $337.714 .418,00$ & $9,9 \%$ & $11,8 \%$ \\
2006 & $44.121 .154,12$ & $6,6 \%$ & $372.285 .061,00$ & $2,7 \%$ & $12,3 \%$ \\
2007 & $46.205 .091,85$ & $4,7 \%$ & $431.113 .603,00$ & $10,2 \%$ & $11,9 \%$ \\
2008 & $52.257 .245,15$ & $13,1 \%$ & $504.962 .891,00$ & $17,1 \%$ & $10,7 \%$ \\
\hline Média & $40.233 .502,50$ & $8,8 \%$ & $348.564 .891,94$ & $\mathbf{1 1 , 0 \%}$ & $10,3 \%$ \\
\hline
\end{tabular}

Fonte: Elaboração Própria com dados da Unica e Fermentec.

industrial da usina. Os outputs foram a produção de açúcar e etanol total (anidro e hidratado), os quais foram padronizados por meio da conversão energética da produção total de açúcar em álcool.

Os resultados permitiram a separação das usinas da amostra em dois grupos distintos, as usinas com índice da PTF maior do que 1 e as usinas com índice da PTF menor do que 1.

O grupo de usinas analisado nesse trabalho, apesar de ser pequeno em número de elementos, apresenta grande relevância perante o setor sucroenergético da região Centro-Sul do Brasil. A importância ocorre pela participação da amostra no total de cana-de-açúcar moída (em toneladas) pelo total de usinas da região, assim como pela considerável proporção em relação ao volume total de açúcar (em toneladas) e etanol (em mil litros) produzidos pela mesma região.

A região Centro-Sul, que inclui os estados das regiões Sudeste, Centro-Oeste e Sul, possui 345 usinas ${ }^{9}$, tornando a amostra com proporção de apenas $4,92 \%$ do total de unidades. Em termos produtivos, a amostra ganha importância, pois representa $11,5 \%$ do total de cana-de-açúcar processada pelas usinas, assim como respondem por aproximadamente $10 \%$ dos produtos finais obtidos. Esse fato pode ser atribuído ao tamanho e importância das unidades selecionadas, pois

9. Total das unidades produtivas de açúcar e etanol, seja conjuntamente ou apenas cada um dos produtos, em 2010. se trata, em grande parte, de usinas de médio e grande porte.

A Tabela 1 apresenta os dados do volume de cana-de-açúcar processado anualmente, entre 2001 e 2008, pelo total de usinas da amostra e pela região Centro-Sul ${ }^{10}$. A amostra é fixa, pois em todos os anos se refere às 17 usinas, enquanto os dados da região Centro-Sul são variáveis, uma vez que houve aumento no número de usinas, principalmente em direção ao Centro-Oeste.

Esse fato pode explicar o motivo do volume de cana-de-açúcar moído pela amostra ter evoluído $72,46 \%$, entre 2001 e 2008, ao passo que o volume processado de cana na região Centro-Sul apresentou, para o mesmo período, crescimento de 106,76\%. Os dados de produção de etanol e açúcar (Tabela 2) também mostram uma participação da amostra de aproximadamente $10 \%$ em relação ao total produzido na região Centro-Sul. A participação caiu relativamente ao longo dos anos devido ao aumento da produção total da região Centro-Sul, que foi marcada pela expansão da área cultivada e instalação de novas usinas na região Centro-Oeste.

10. Considera-se os estados de MG, ES, RJ, SP, SC, RS, MT, MS e GO (Unica, 2011). 
Tabela 2. Comparativo entre a produção de etanol e açúcar na região Centro-Sul e na amostra - 2001 - 2008

\begin{tabular}{|c|c|c|c|c|c|}
\hline Ano & Amostra & $\begin{array}{c}\text { Taxa de Crescimento } \\
\text { Anual } \\
\end{array}$ & Centro-Sul & $\begin{array}{c}\text { Taxa de Crescimento } \\
\text { Anual }\end{array}$ & $\begin{array}{c}\text { Participação Amostra/ } \\
\text { Centro-Sul }\end{array}$ \\
\hline \multicolumn{6}{|c|}{ Etanol } \\
\hline 2001 & $1.225 .605,78$ & - & $10.176 .290,00$ & - & $12,0 \%$ \\
\hline 2002 & $1.354 .537,30$ & $10,5 \%$ & $11.152 .084,00$ & $9,6 \%$ & $12,1 \%$ \\
\hline 2003 & $1.629 .155,48$ & $20,3 \%$ & $13.068 .637,00$ & $17,2 \%$ & $12,5 \%$ \\
\hline 2004 & $1.603 .166,11$ & $-1,6 \%$ & $13.591 .355,00$ & $4,0 \%$ & $11,8 \%$ \\
\hline 2005 & $1.784 .256,74$ & $11,3 \%$ & $14.352 .542,00$ & $5,6 \%$ & $12,4 \%$ \\
\hline 2006 & $1.881 .398,89$ & $5,4 \%$ & $16.006 .345,00$ & $11,5 \%$ & $11,8 \%$ \\
\hline 2007 & $2.044 .712,58$ & $8,7 \%$ & $20.333 .466,20$ & $27,0 \%$ & $10,1 \%$ \\
\hline 2008 & 2.377.458,59 & $16,3 \%$ & $25.101 .963,00$ & $23,5 \%$ & $9,5 \%$ \\
\hline Média & $1.737 .536,43$ & $10,1 \%$ & $15.472 .835,28$ & $14,1 \%$ & $11,2 \%$ \\
\hline \multicolumn{6}{|c|}{ Açúcar } \\
\hline 2001 & $2.056 .629,26$ & - & $15.972 .162,00$ & - & $12,9 \%$ \\
\hline 2002 & 2.477.244,93 & $20,5 \%$ & $18.778 .055,00$ & $17,6 \%$ & $13,2 \%$ \\
\hline 2003 & $2.644 .673,28$ & $6,8 \%$ & $20.420 .477,00$ & $8,7 \%$ & $13,0 \%$ \\
\hline 2004 & 2.793.281,98 & $5,6 \%$ & $22.085 .132,00$ & $8,2 \%$ & $12,6 \%$ \\
\hline 2005 & $2.875 .345,02$ & $2,9 \%$ & $22.084 .810,00$ & $0,0 \%$ & $13,0 \%$ \\
\hline 2006 & $3.147 .859,62$ & $9,5 \%$ & $25.784 .133,00$ & $16,8 \%$ & $12,2 \%$ \\
\hline 2007 & $3.094 .552,05$ & $-1,7 \%$ & $26.200 .606,00$ & $1,6 \%$ & $11,8 \%$ \\
\hline 2008 & $3.149 .597,34$ & $1,8 \%$ & $26.749 .819,39$ & $2,1 \%$ & $11,8 \%$ \\
\hline Média & $2.779 .897,93$ & $6,5 \%$ & $22.259 .399,30$ & $7,8 \%$ & $12,5 \%$ \\
\hline
\end{tabular}

Fonte: Elaboração própria com dados dos autores deste artigo e da Unica.

Na Tabela 2 ainda é possível verificar que a produção de etanol cresceu $147 \%$ ao longo do período na região Centro-Sul, ao passo que a produção de açúcar foi ampliada em $67 \%$. De tal modo, a produção de etanol do grupo analisado cresceu $84 \%$, enquanto a produção de açúcar ampliou em $43 \%$. Esse fato reflete a discussão já realizada previamente sobre a maior demanda por etanol nos mercados doméstico e internacional, o que tem refletido na construção de unidades produtivas (greenfields) dedicadas apenas à produção de etanol (destilarias), como verificado no Centro-Oeste.

Seguindo a Tabela 3, o crescimento do volume moído foi de $72 \%$ para o período e o número de empregados nas unidades da amostra cresceu $47,4 \%$ no mesmo período, no conjunto total da amostra. Sobre a produtividade do trabalho, é possível afirmar que a quantidade de cana moída por trabalhador na indústria aumentou $17 \%$, entre 2001 e 2008 , partindo 6.373 toneladas/ empregado, em 2001, para 7.455 toneladas/

Tabela 3. Dados de Produção e Empregados na Indústria - Amostra - 2001 - 2008

\begin{tabular}{ccccc}
\hline Ano & Cana Moída (T) & Álcool $(\mathbf{m i l} \mathbf{L})$ & Açúcar $(\mathbf{T})$ & Empregados \\
\hline 2001 & $28.993 .456,44$ & $1.225 .605,78$ & $2.056 .629,26$ & 4.549 \\
2002 & $32.816 .567,32$ & $1.354 .537,30$ & $2.477 .244,93$ & 5.275 \\
2003 & $37.155 .489,97$ & $1.629 .155,48$ & $2.644 .673,28$ & 5.559 \\
2004 & $38.910 .283,14$ & $1.603 .166,11$ & $2.793 .281,98$ & 5.779 \\
2005 & $41.408 .731,99$ & $1.784 .256,74$ & $2.875 .345,02$ & 5.922 \\
2006 & $44.121 .154,12$ & $1.881 .398,89$ & $3.147 .859,62$ & 6.277 \\
2007 & $46.205 .091,85$ & $2.044 .712,58$ & $3.094 .552,05$ & 6.667 \\
2008 & $52.257 .245,15$ & $2.377 .458,59$ & $3.149 .597,34$ & 6.707 \\
\hline
\end{tabular}

Fonte: Elaboração própria a partir de dados primários. 
empregado, em 2008. Esse fato apresenta indicativos de que a produção industrial tornou-se mais eficiente na produtividade do trabalho, possivelmente devido a maiores e melhores investimentos no processo produtivo, otimizando o uso da mão de obra.

Após essa breve introdução sobre a importância da amostra, seguimos para a apresentação e discussão dos resultados da análise e modelagem DEA-Malmquist, no modelo BCC orientado a insumos. Como já mencionado, o índice de Malmquist avalia os índices de produtividade ao longo do tempo, decompondo-os em índices que captam variação da eficiência técnica e mudanças tecnológicas. A decomposição contribui para uma análise mais detalhada das alterações nos índices de produtividade, pois é possível averiguar se a variação é decorrente de alterações na fronteira tecnológica (inovações) ou melhoria na eficiência técnica ou dos dois simultaneamente.

A Tabela 4 apresenta os índices da produtividade total dos fatores para toda a amostra pelos pares de anos, com a média anual negativa de $0,2 \%$ e redução ao longo dos anos de 2001 a
2008. O desempenho das usinas começou bem em 2002, tendo apresentado queda em 2003/04, fato que é observado em quase todas as unidades analisadas. Assim como no ano deem 2006/07, quando as usinas no geral vieram de uma boa situação em 2004 e 2005, apresentando queda no ano posterior.

A explicação para o desempenho da amostra ao longo do período é de difícil obtenção, mas analisando as Tabelas 5 e 6 adiante, é possível inferir que em 2003/04 houve deslocamento na fronteira de eficiência para cima, pelo valor maior do que 1 na componente mudança técnica (Tabela 5), ao passo que a componente eficiência técnica apresentou crescimento negativo (Tabela 6), ou seja, as usinas em 2003/04 não conseguiram alcançar a fronteira, resultando em um valor médio final da PTF menor do que 1, uma vez que a PTF pelo Malmquist é uma média geométrica entre as duas componentes.

Já em 2006/07 houve novamente redução da PTF, em que, através da decomposição dos índices, é possível inferir que a fronteira de eficiência pode ter sofrido um deslocamento para

Tabela 4. Índice de Produtividade de Malmquist - 2001 - 2008

\begin{tabular}{cccccccccc}
\hline Usina & $\mathbf{2 0 0 1 / 0 2}$ & $\mathbf{2 0 0 2 / 0 3}$ & $\mathbf{2 0 0 3 / 0 4}$ & $\mathbf{2 0 0 4 / 0 5}$ & $\mathbf{2 0 0 5 / 0 6}$ & $\mathbf{2 0 0 6 / 0 7}$ & $\mathbf{2 0 0 7 / 0 8}$ & Média & DP \\
\hline 1 & 1,020 & 0,954 & 0,987 & 0,999 & 1,047 & 0,948 & 0,987 & 0,991 & 0,035 \\
2 & 1,029 & 1,025 & 0,982 & 0,999 & 1,008 & 1,006 & 0,976 & 1,003 & 0,020 \\
3 & 0,992 & 1,017 & 0,953 & 1,006 & 1,034 & 1,014 & 0,737 & 0,959 & 0,104 \\
4 & 0,992 & 1,04 & 0,977 & 1,067 & 0,995 & 0,929 & 0,998 & 0,999 & 0,044 \\
5 & 1,107 & 1,138 & 0,915 & 1,008 & 1,032 & 1,002 & 1,010 & 1,028 & 0,074 \\
6 & 1,089 & 0,97 & 0,896 & 1,004 & 1,093 & 0,934 & 0,963 & 0,990 & 0,075 \\
7 & 1,074 & 1,006 & 0,949 & 1,154 & 0,874 & 0,968 & 1,011 & 1,002 & 0,090 \\
8 & 0,981 & 1,024 & 0,986 & 1,053 & 0,989 & 0,979 & 0,997 & 1,001 & 0,027 \\
9 & 1,047 & 1,007 & 0,963 & 1,006 & 1,023 & 0,991 & 0,979 & 1,002 & 0,028 \\
10 & 1,069 & 1,059 & 1,086 & 0,87 & 1,033 & 0,967 & 0,979 & 1,006 & 0,076 \\
11 & 1,027 & 0,999 & 0,982 & 0,961 & 1,032 & 0,995 & 0,994 & 0,998 & 0,025 \\
12 & 1,023 & 0,957 & 1,013 & 0,965 & 1,015 & 0,968 & 0,982 & 0,989 & 0,027 \\
13 & 1,017 & 0,989 & 0,881 & 1,120 & 1,018 & 0,99 & 1,023 & 1,003 & 0,070 \\
14 & 1,026 & 0,988 & 0,964 & 0,992 & 1,069 & 0,973 & 0,987 & 0,999 & 0,036 \\
15 & 0,975 & 1,012 & 1,012 & 0,96 & 1,085 & 1,023 & 1,006 & 1,010 & 0,040 \\
16 & 1,016 & 1,046 & 0,913 & 1,001 & 1,029 & 1,006 & 1,036 & 1,006 & 0,044 \\
17 & 1,058 & 0,965 & 1,007 & 1,011 & 0,904 & 1,038 & 0,941 & 0,988 & 0,055 \\
\hline Média & $\mathbf{1 , 0 3 1}$ & $\mathbf{1 , 0 1 1}$ & $\mathbf{0 , 9 6 7}$ & $\mathbf{1 , 0 0 8}$ & $\mathbf{1 , 0 1 5}$ & $\mathbf{0 , 9 8 4}$ & $\mathbf{0 , 9 7 4}$ & $\mathbf{0 , 9 9 8}$ & $\mathbf{0 , 0 2 4}$ \\
\hline DP & $\mathbf{0 , 0 3 8}$ & $\mathbf{0 , 0 4 5}$ & $\mathbf{0 , 0 5 0}$ & $\mathbf{0 , 0 6 4}$ & $\mathbf{0 , 0 5 6}$ & $\mathbf{0 , 0 3 0}$ & $\mathbf{0 , 0 6 6}$ & $\mathbf{0 , 0 1 4}$ &
\end{tabular}

Fonte: Elaboração própria com dados da Fermentec e Unica. 
Tabela 5. Componente Mudança Técnica - 2002 - 2008

\begin{tabular}{ccccccccc}
\hline Usina & $\mathbf{2 0 0 1 / 0 2}$ & $\mathbf{2 0 0 2 / 0 3}$ & $\mathbf{2 0 0 3 / 0 4}$ & $\mathbf{2 0 0 4 / 0 5}$ & $\mathbf{2 0 0 5 / 0 6}$ & $\mathbf{2 0 0 6 / 0 7}$ & $\mathbf{2 0 0 7 / 0 8}$ & Média \\
\hline 1 & 1,047 & 0,965 & 1,025 & 1,082 & 0,915 & 0,967 & 1,009 & 1,000 \\
2 & 1,047 & 0,965 & 1,032 & 1,045 & 0,933 & 0,998 & 0,998 & 1,002 \\
3 & 1,047 & 0,965 & 1,032 & 1,045 & 0,933 & 0,995 & 1,000 & 1,002 \\
4 & 0,998 & 1,034 & 0,977 & 1,067 & 0,995 & 0,929 & 0,998 & 0,999 \\
5 & 1,042 & 1,135 & 0,948 & 1,025 & 1,017 & 0,965 & 1,010 & 1,019 \\
6 & 1,047 & 0,970 & 0,992 & 1,062 & 0,933 & 0,963 & 1,018 & 0,997 \\
7 & 1,026 & 1,051 & 0,968 & 1,084 & 0,928 & 0,973 & 0,997 & 1,003 \\
8 & 1,047 & 0,965 & 0,971 & 1,059 & 0,972 & 0,973 & 0,997 & 0,997 \\
9 & 1,047 & 0,965 & 0,978 & 1,102 & 0,922 & 0,974 & 0,997 & 0,996 \\
10 & 1,047 & 0,965 & 1,032 & 1,051 & 0,933 & 0,967 & 1,024 & 1,002 \\
11 & 1,038 & 0,975 & 0,968 & 1,071 & 0,955 & 0,969 & 0,992 & 0,994 \\
12 & 1,047 & 0,965 & 0,999 & 1,081 & 0,923 & 0,969 & 1,005 & 0,997 \\
13 & 1,047 & 0,965 & 1,032 & 1,045 & 0,933 & 0,979 & 1,014 & 1,001 \\
14 & 1,047 & 0,965 & 1,023 & 10,48 & 0,933 & 0,966 & 1,020 & 0,999 \\
15 & 1,047 & 0,965 & 1,032 & 1,045 & 0,933 & 0,995 & 1,006 & 1,003 \\
16 & 1,047 & 0,965 & 1,032 & 1,045 & 0,933 & 0,996 & 1,002 & 1,002 \\
17 & 1,047 & 0,965 & 1,032 & 1,045 & 0,933 & 0,979 & 1,012 & 1,001 \\
\hline Média & $\mathbf{1 , 0 4 2}$ & $\mathbf{0 , 9 8 4}$ & $\mathbf{1 , 0 0 4}$ & $\mathbf{1 , 0 5 9}$ & $\mathbf{0 , 9 4 2}$ & $\mathbf{0 , 9 7 4}$ & $\mathbf{1 , 0 0 6}$ & $\mathbf{1 , 0 0 1}$ \\
\hline
\end{tabular}

Fonte: Elaboração própria com dados da Fermentec e Unica.

baixo, resultando no catching-up das usinas, pois a componente apresentou crescimento positivo. Importante considerar que, apesar do alcance da eficiência por parte das usinas, essa fronteira encontrava-se em um nível baixo.

Outra possível inferência para a queda entre 2003 e 2004 pode ser o bom nível alcançado pela amostra em 2003, que havia ampliado a moagem de cana em $13,2 \%$, com obtenção de uma produção final também por volta de $13 \%$ maior. Esse bom nível fez reduzir o índice da PTF no ano seguinte, pois o crescimento no volume moído foi de menos de $5 \%$, com redução no volume de etanol produzido, fato que pode ser explicado pela oscilação de preços na safra.

$\mathrm{O}$ índice de produtividade total dos fatores, Malmquist, mede como a firma consegue combinar os seus recursos, no caso aqui analisado, como consegue combinar o uso do insumo cana-de-açúcar com o número de empregados na área industrial para obter um dado nível de produto. Assim, a redução no volume de cana moída e a redução no produto final não implica na redução do número de empregados, pois eles são contratados permanentemente e a área industrial não possui controle totalmente eficaz sobre a produtividade da área agrícola para realizar um planejamento consistente ${ }^{11}$.

Em 2007 observa-se queda semelhante, que possivelmente pode ser explicada pelo baixo crescimento no volume moído pela indústria, com menor volume produzido de açúcar em relação ao ano anterior, fato que pode ser novamente explicado pela queda de preço no açúcar cristal e etanol em 2006. O comportamento do índice apresentou muita variabilidade ao longo dos anos para o conjunto da amostra e para cada firma isoladamente, que pode ser explicado pelas flutuações naturais observadas em estudos que envolvem esse método, pois o método DEA é muito sensível a mudanças nos insumos e produtos avaliados ano a ano.

A decomposição do índice de Malmquist entre mudança técnica e eficiência técnica permite verificar qual componente contribuiu mais e qual contribuiu menos para o resultado final da PTF, como mostram as Tabelas 5 e 6 .

\footnotetext{
11. As usinas ainda estão em estágio inicial no planejamento de safra pela falta de instrumentos e tecnologias amplamente testadas e disseminadas.
} 
Tabela 6. Componente Eficiência Técnica

\begin{tabular}{ccccccccc}
\hline Usina & $\mathbf{2 0 0 1 / 0 2}$ & $\mathbf{2 0 0 2 / 0 3}$ & $\mathbf{2 0 0 3 / 0 4}$ & $\mathbf{2 0 0 4 / 0 5}$ & $\mathbf{2 0 0 5 / 0 6}$ & $\mathbf{2 0 0 6 / 0 7}$ & $\mathbf{2 0 0 7 / 0 8}$ & Média \\
\hline 1 & 0,975 & 0,988 & 0,963 & 0,923 & 1,145 & 0,980 & 0,978 & 0,991 \\
2 & 0,983 & 1,062 & 0,951 & 0,956 & 1,080 & 1,008 & 0,978 & 1,001 \\
3 & 0,948 & 1,054 & 0,924 & 0,962 & 1,108 & 1,019 & 0,737 & 0,958 \\
4 & 0,994 & 1,006 & 1,000 & 1,000 & 1,000 & 1,000 & 1,000 & 1,000 \\
5 & 1,062 & 1,003 & 0,965 & 0,983 & 1,015 & 1,038 & 1,000 & 1,009 \\
6 & 1,040 & 1,000 & 0,903 & 0,945 & 1,171 & 0,970 & 0,946 & 0,993 \\
7 & 1,047 & 0,958 & 0,981 & 1,065 & 0,942 & 0,995 & 1,013 & 0,999 \\
8 & 0,937 & 1,061 & 1,015 & 0,994 & 1,018 & 1,007 & 1,000 & 1,004 \\
9 & 1,000 & 1,043 & 0,985 & 0,913 & 1,109 & 1,018 & 0,981 & 1,005 \\
10 & 1,021 & 1,097 & 1,052 & 0,827 & 1,107 & 0,999 & 0,955 & 1,004 \\
11 & 0,989 & 1,024 & 1,015 & 0,898 & 1,081 & 1,026 & 1,002 & 1,004 \\
12 & 0,978 & 0,992 & 1,014 & 0,893 & 1,100 & 0,999 & 0,977 & 0,992 \\
13 & 0,972 & 1,025 & 0,853 & 1,071 & 1,091 & 1,012 & 1,008 & 1,002 \\
14 & 0,980 & 1,024 & 0,942 & 0,947 & 1,146 & 1,007 & 0,968 & 1,000 \\
15 & 0,932 & 1,049 & 0,980 & 0,918 & 1,163 & 1,028 & 1,000 & 1,007 \\
16 & 0,971 & 1,084 & 0,885 & 0,958 & 1,103 & 1,009 & 1,034 & 1,004 \\
17 & 1,011 & 1,000 & 0,976 & 0,967 & 0,969 & 1,060 & 0,930 \\
\hline Média & $\mathbf{0 , 9 9 0}$ & $\mathbf{1 , 0 2 7}$ & $\mathbf{0 , 9 6 4}$ & $\mathbf{0 , 9 5 2}$ & $\mathbf{1 , 0 7 7}$ & $\mathbf{1 , 0 1 0}$ & $\mathbf{0 , 9 6 9}$ & $\mathbf{0 , 9 9 8}$ \\
\hline
\end{tabular}

Fonte: Elaboração própria com dados da Fermentec e Unica.

Por sua vez, a Tabela 6 apresenta a componente eficiência técnica, que também pode ser chamada de catch-up index, que mede quanto próximo da fronteira de eficiência se encontra a firma. Em termos geométricos, a eficiência técnica significa a distância da firma em relação à fronteira de produção, em outras palavras, significa as boas práticas realizadas pelas usinas, ou seja, a variação positiva nesse componente indica que a usina apresentou boas práticas.

Assim sendo, na análise do conjunto das usinas o valor positivo significa que estas estão convergindo para um processo tecnológico semelhante ao das usinas da fronteira de eficiência, ou seja, as usinas apresentam catching-up. A componente mudança técnica reflete a capacidade de modernização, em que a melhora nesse índice indica um deslocamento para cima da fronteira de eficiência (produto médio máximo), assim como a piora indica uma contração na fronteira de eficiência.

A Tabela 7 apresenta o resultado da produtividade total dos fatores para cada usina na média do período de 2001 a 2008. Entre as usinas analisadas, o melhor desempenho, em termos de crescimento médio da PTF, foi registrado para a usina 5, com 2,8\% de crescimento médio anual do índice da PTF, enquanto o pior foi para a usina 3, com crescimento médio anual negativo de $4,1 \%$. O detalhamento das firmas será realizado mais adiante.

Observa-se que, apesar de a média do período ter sido negativa, a maior parte das usinas apresentou crescimento positivo da PTF, tendo sido nove usinas com PTF maior do que 1 e oito usinas com PTF menor do que 1. Observando a participação dos componentes eficiência técnica e mudança técnica, observa-se que a maior participação se deu pela componente eficiência, ou seja, o que se observou no período foi a predominância do catching-up em relação à fronteira de eficiência do período, em vez de constantes e substantivos deslocamentos da fronteira.

Importante considerar que a presente análise centra-se entre as safras, nas quais é possível haver inúmeras variações, sejam elas inerentes às condições climáticas, às condições do mercado em que competem ou ainda na qualidade da matéria-prima, que são afetadas de forma diferente em cada situação e que não são captadas pelo modelo. 
Tabela 7. Produtividade Total dos Fatores - Média - 2001 - 2008

\begin{tabular}{cccccc}
\hline Usina & Eficiência Técnica & Mudança Técnica & Eficiência Técnica Pura & Eficiência de Escala & PTF \\
\hline 1 & 0,991 & 1,000 & 0,994 & 0,997 & 0,991 \\
2 & 1,001 & 1,002 & 0,998 & 1,004 & 1,003 \\
3 & 0,958 & 1,002 & 0,958 & 1,000 & 0,959 \\
4 & 1,000 & 0,999 & 1,000 & 1,000 & 0,999 \\
5 & 1,009 & 1,019 & 1,000 & 1,009 & 1,028 \\
6 & 0,993 & 0,997 & 1,000 & 0,993 & 0,990 \\
7 & 0,999 & 1,003 & 0,993 & 1,006 & 1,002 \\
8 & 1,004 & 0,997 & 1,000 & 1,004 & 1,001 \\
9 & 1,005 & 0,996 & 1,004 & 1,001 & 1,002 \\
10 & 1,004 & 1,002 & 1,005 & 0,999 & 1,006 \\
11 & 1,004 & 0,994 & 1,000 & 1,004 & 0,998 \\
12 & 0,992 & 0,997 & 0,999 & 0,992 & 0,989 \\
13 & 1,002 & 1,001 & 1,001 & 1,001 & 1,003 \\
14 & 1,000 & 0,999 & 1,003 & 0,997 & 0,999 \\
15 & 1,007 & 1,003 & 1,000 & 1,007 & 1,010 \\
16 & 1,004 & 1,002 & 1,002 & 1,002 & 1,006 \\
17 & 0,987 & 1,001 & 0,986 & 1,000 & 0,988 \\
\hline Média & $\mathbf{0 , 9 9 8}$ & $\mathbf{1 , 0 0 1}$ & $\mathbf{0 , 9 9 7}$ & $\mathbf{1 , 0 0 1}$ & $\mathbf{0 , 9 9 8}$ \\
\hline Máximo & $\mathbf{1 , 0 0 9}$ & $\mathbf{1 , 0 1 9}$ & $\mathbf{1 , 0 0 0}$ & $\mathbf{1 , 0 0 9}$ & $\mathbf{1 , 0 2 8}$ \\
Mínimo & $\mathbf{0 , 9 5 8}$ & $\mathbf{1 , 0 0 2}$ & $\mathbf{0 , 9 5 8}$ & $\mathbf{1 , 0 0 0}$ & $\mathbf{0 , 9 5 9}$ \\
DP & $\mathbf{0 , 0 1 2}$ & $\mathbf{0 , 0 0 5}$ & $\mathbf{0 , 0 1 1}$ & $\mathbf{0 , 0 0 5}$ & $\mathbf{0 , 0 1 4}$ \\
\hline
\end{tabular}

Fonte: Elaboração própria com dados da Fermentec e Unica.

Essa análise converge com a ideia de mudança de paradigma que resultou em um ambiente muito heterogêneo no que diz respeito às práticas de gestão e aos resultados obtidos pelas firmas que compõem o setor. Além da heterogeneidade produtiva, observa-se também existência de empresas tecnologicamente muito atrasadas, com baixa eficiência, coexistindo com empresas muito eficientes, que optaram pelo maior desenvolvimento de suas técnicas de gestão e tecnologia produtiva, formando um universo de muita heterogeneidade sob esse aspecto (SHIKIDA, NEVES e REZENDE, 2002).

\section{Conclusões}

Primeiramente, é necessário considerar que a amostra analisada neste trabalho é um grupo de usinas que procuraram os serviços de uma consultoria referência no setor sucroenergético como provedora de melhorias na eficiência dos processos produtivos. Assim sendo, a amostra possui um viés por analisar usinas em busca de eficiência, ou ainda, usinas que estavam em busca de melhorias, o que não significou necessariamente a sua obtenção.

A análise de cada usina em particular trouxe a sensação que a amostra congregou empresas em boas condições produtivas, entretanto, percebeu-se que quase nenhuma apresentou ganhos de produtividade ao longo do período devido à componente mudança técnica, ou seja, através de inovações tecnológicas. Também foi possível observar na amostra das 17 usinas que a maioria das usinas com índice maior do que 1 na produtividade total dos fatores, através do índice de Malmquist, o teve em função de melhorias com as boas práticas, ou seja, as usinas fizeram o catching-up em relação às mais eficientes.

Essa análise converge com a ideia de outros trabalhos na área, em que a mudança de paradigma resultou em um ambiente muito heterogêneo no que diz respeito às práticas de gestão e os resultados obtidos pelas firmas que compõem o setor, além da coexistência de empresas tecnolo- 
gicamente muito atrasadas com empresas muito eficientes. Em termos técnicos, a análise dos grupos com o índice de produtividade maior do que 1 , ou seja, as usinas mais eficientes da amostra, revela que a maior contribuição para esse crescimento foi a eficiência técnica seguida da eficiência de escala, ou seja, o que fez a produtividade desse grupo manter taxas positivas de crescimento ao longo do período foi preponderantemente a eficiência obtida pelas usinas, ou seja, a convergência em busca das melhores práticas pelas usinas localizadas na fronteira de eficiência.

A componente mudança tecnológica foi preponderante na usina 5, que apresentou o melhor índice da amostra, o que significa que essa realizou inovações que a possibilitou deslocar a fronteira tecnológica. Outras usinas também tiveram relativa participação desse componente, porém, em menor medida, o que corrobora outros trabalhos na área, os quais dizem que a agroindústria canavieira é sabidamente amparada de boa qualidade técnica e de baixos custos, entretanto, apresenta domínio apenas das tecnologias básicas e intermediárias, deixando a desejar nas capacidades tecnológicas avançadas.

Embora seja de amplo conhecimento pelos profissionais do setor sucroenergético a importância do investimento em pesquisa e desenvolvimento para a sua sobrevivência, a motivação para investimentos robustos em inovação tecnológica não existe para grande parte dos grupos de usinas. Assim sendo, é possível caracterizar a amostra como composta em sua maioria por followers, ou seja, as usinas não criam e adotam inovações radicais, elas apenas seguem um movimento conjunto em direção a tecnologias já testadas no mercado e de comprovada eficiência por outras usinas.

\section{Referências}

ABARCA, C. D. Inovações tecnológicas na agroindústria da cana-de-açúcar no Brasil. Agroindústria da Cana-de-Açúcar - Estratégia, Organizações e Tecnologia. COPPE/UFRJ, 2003.
AIGNER, D. J. e CHU. On Estimating the Industry Production Function. American Economic Review, v. 58, p. 826-8S9, 1968.

BRUZONI JR., A. C. e GONÇALVES, R. M. (2011) Eficiência produtiva e análise econômica e financeira de usinas de cana-de-açúcar do Estado de São Paulo. $11^{\circ}$ Congresso USP de Controladoria e Contabilidade. USP,São Paulo.

CANO, A. e TUPY, O. Eficiência produtiva de usinas de açúcar e álcool do Estado de São Paulo. XLIII Congresso da Sober. Sociedade Brasileira de Economia e Sociologia Rural. Ribeirão Preto, 2005.

CAVES, D. W., CHRISTENSEN, L. R. e DIEWERT, W. E. The Economic Theory of Index Numbers and the Measurement of Input, Output and Productivity. Econometrica, v. 50, p. 1393-1414, 1982.

COELLI, T. J. A guide to DEAP version 2.1: a data envelopment analysis program. Armidale, Austrália: University of New England. 1996. 49p. CEPA Working Papers, 1996.

., RAO, D. S. P. e BATTESE, G. E. An introduction to efficiency and productivity analysis. Boston: Kluwer Academic, 1998. 275 p.

DEBREU, G. The coefficient of resource utilization. Econometrica, v. 19, n. 3, p. 273-292, 1951.

DOSI, G. Technical change and industrial transformation. St. Martin's Press (New York), 1984.

FÄRE,R.etal.Productivity Growth, TechnicalProgress, and EfficiencyChangeinIndustrializedCountries.TheAmerican Economic Review, v. 84, n. 1, p. 66-83, 1994.

FARRELL, M. J. The Measurement of Productive Efficiency. Journal of the Royal Statistical Society. Series A (General), v. 120, n. 3, p. 253-290, 1957.

KOOPMANS, T. C. An analysis of production as an efficient combination of activities. In: KOOPMANS, T. C. (Ed.). Activity Analysis of Production and Allocation. Jhon Wiley and Sons, Inc., 1951.

LEVINS, R. A. e COCHRANE, W. W. The treadmill revisited. Land Economics, Madison, v. 72, n. 4, p. 550553, nov. 1996.

MALERBA, F. Innovation and the dynamics and evolution of industries: Progress and challenges. International Journal of Industrial Organization, v. 25, p. $675-699,2006$.

MALMQUIST, S. Index numbers and indifference surfaces. Trabajos de Estadistica, v. 4, p. 209-242, 1953. 
MELLO, E. P. G. Produtividade total dos fatores, mudança técnica, eficiência técnica e eficiência de escala na indústria brasileira, 1996-2000. Tese (Mestrado) Centro de Desenvolvimento e Planejamento Regional. Faculdade de Ciências Econômicas/UFMG, 2003.

MELO JÚNIOR, A. M. Índice de Malmquist aplicado na avaliação de Produtividade de Soja da Região de Guarapuava. Tese (Mestrado), Setor de Ciências Exatas e Tecnologia/ UFPR, 2005.

MIGLINO, M. A. P. Inovação: o local importa? Um ensaio sobre os nexos entre inovação e espaço segundo contemporâneos selecionados. Dissertação (Mestrado), DPCT/UNICAMP, 2003.

NELSON, R. e WINTER, S. An evolutionary theory of economic change. 6. ed. Cambridge: Harvard University Press, 1982. 437 p.

RISSARDI JR., D. J. e SHIKIDA, P. F. A. A agroindústria canavieira do Paraná pós-desregulamentação: uma abordagem neo-schumpeteriana. RER, Rio de Janeiro, v. 45 , n. 2 , p. $445-473,2007$.
ROSENBERG, N. Inside the black box: technology and economics. Cambridge: Cambridge University Press, 1982. 304 p.

SALGADO JUNIOR, A. P., BONACIM, C. A. G. e PACAGNCCA JUNIOR, A. C. Aplicação da análise envoltória de dados (DEA) para avaliação de eficiência de usinas de açúcar e álcool da região nordeste de São Paulo. Organizações Rurais e Agroindustriais/Rural, v. 11, n. 3, p.494-513, 2009.

SESMERO, J. P., PERRIK, R. K. e FULGINITI, L. E. Economic and Marketing Efficiency Among Corn Ethanol Plants. Australian Agricultural and Resource Economics Society>2011 Conference (55th), February 8-11, Melbourne, Australia.

SHIKIDA, P. F. A., NEVES, M. F. e REZENDE, R. A. Notas sobre dinâmica tecnológica e agroindústria canavieira no Brasil. In: MORAES, M. A. F. D. e SHIKIDA, P. F. A. (Orgs.). Agroindústria Canavieira no Brasil: evolução, desenvolvimento e desafios. São Paulo: Atlas, 2002. 
